\title{
Involvement of the TGF- $\beta 1$ pathway in caveolin-1-associated regulation of head and neck tumor cell metastasis
}

\author{
JINJIE SUN ${ }^{1,2}$, YONGTIAN LU ${ }^{1}$, CHANGYUN YU ${ }^{2}$, TING XU ${ }^{2}$, \\ GUOHUI NIE ${ }^{1}$, BEIPING MIAO ${ }^{1}$ and XIN ZHANG ${ }^{2}$ \\ ${ }^{1}$ Department of Otolaryngology, Shenzhen Second People's Hospital, The First Affiliated Hospital \\ of Shenzhen University, Shenzhen, Guangdong 518035; ${ }^{2}$ Department of Otolaryngology, \\ Xiangya Hospital, Central South University, Changsha, Hunan 410008, P.R. China
}

Received March 26, 2018; Accepted April 5, 2019

DOI: $10.3892 / 01.2019 .11187$

\begin{abstract}
Head and neck squamous cell carcinoma (HNSCC) is the sixth most frequent malignancy with a 5-year survival rate of $54 \%$. Therefore, disease management improvement is required. The present study aimed to assess the role of caveolin-1 (Cav-1) in the metastasis of head and neck tumor cells. Short hairpin RNA was used to silence Cav-1 expression in Tu686 cells. Proliferation, migration, invasion, morphology and the levels of effector proteins were assessed in cells. Upon Cav-1 silencing, E-cadherin levels were decreased, while vimentin levels were significantly increased. Cell migration, quantified by wound healing and Transwell assays, was significantly increased. Meanwhile, Cav-1 and transforming growth factor $\beta 1$ (TGF- $\beta 1$ ) receptor were identified to be co-localized. In addition, Cav-1knockdown resulted in increased phosphorylation of SMAD family member $2(\mathrm{P}<0.05)$, a downstream effector of TGF- $\beta$ signaling. In addition, there was a mutual regulation, with increasing TGF- $\beta 1$ levels leading to a dose-dependent decrease of Cav-1 expression levels $(\mathrm{P}<0.05)$. These findings indicate that Cav-1 inhibits cell metastasis in HNSCC, suggesting the involvement of the TGF- $\beta$ signaling pathway.
\end{abstract}

\section{Introduction}

It has been reported that $>90 \%$ of head and neck malignant tumor cases are squamous cell carcinoma (1-3). Head and

Correspondence to: Dr Xin Zhang, Department of Otolaryngology, Xiangya Hospital, Central South University, 87 Xiangya Road, Changsha, Hunan 410008, P.R. China

E-mail: xinzhang@csu.edu.cn

Abbreviations: shRNA, short hairpin RNA; Cav-1, caveolin-1; EMT, epithelial-to-mesenchymal transition; FACS, fluorescence activated cell sorting analysis; HNSCC, head and neck squamous cell carcinoma; TGF- $\beta 1$, transforming growth factor $\beta 1$

Key words: caveolin-1, head and neck squamous cell carcinoma, epithelial-mesenchymal transition, transforming growth factor $\beta 1$ signaling pathway, invasiveness and metastasis neck squamous cell carcinoma (HNSCC) mainly arises from the epithelium of the oral cavity, oropharynx and larynx (4). Currently, treatment for HNSCC involves surgery, radiotherapy and adjuvant chemotherapy. Despite continuous improvements and updates in treatment, the five-year survival rate of patients with HNSCC has not improved (5). This is partly due to the occurrence of early tumor metastasis $(6,7)$. Lymph node metastasis has been reported in $50 \%$, with distant metastasis observed in $20-30 \%$ of patients with HNSCC in the two years following therapy $(8,9)$. However, almost two thirds of patients with HNSCC, who receive combined treatment of chemo- and radiotherapy succumb within three years; therefore, further improvements in the treatment and management of HNSCC are required (10). Although a number of genes and pathways are aberrantly expressed in HNSCC, including tumor protein 53, cyclin dependent kinase inhibitor $2 \mathrm{~A}$, Ras, nuclear factor $\kappa \mathrm{B}$ and epidermal growth factor receptor, an understanding of the functional underlying mechanisms by which they regulate metastasis and recurrence remains undetermined (11-15). Therefore, it is crucial to identify proteins that regulate metastasis and understand their functional mechanisms, which in turn would promote the development of novel prognostic biomarkers and therapeutic approaches for the disease.

Epithelial-to-mesenchymal transition (EMT) is a crucial process in metastasis, as cells acquire mesenchymal and fibroblast-like properties and indicate increased motility and reduced adhesion (16-18). A number of pathways have been reported to induce EMT, including transforming growth factor $\beta 1$ (TGF- $\beta 1$ )-mediated signaling (19-21). Although TGF- $\beta 1$ activates multiple signaling pathways, the main one for EMT regulation is as follows: TGF- $\beta 1$ induces its own receptor, leading to the activation of downstream signaling molecules, which reduces SMAD family member $2(\mathrm{Smad} 2) / \mathrm{Smad} 3$ phosphorylation, followed by Smad2/Smad3 forming heterodimers with Smad4 (22). This complex enters the nucleus, upregulates nuclear transcription factors and inhibits the epithelial cell marker E-cadherin, ultimately leading to EMT and tumor cell invasion and metastasis (23). Therefore, the aim of the present study was to identify a key regulator of TGF- $\beta 1$-mediated cell signaling to prevent EMT and metastasis.

Caveolin-1 (Cav-1), a 21-24 kDa integral membrane protein and a principal structural component of caveolae, serves a 
critical role in TGF- $\beta$-associated transactivation of epidermal growth factor (EGF) receptor signaling in hepatocytes; in addition, caveolin was reported to suppress TGF- $\beta$ signaling, with TGF- $\beta$ receptors known to be endocytosed in a caveolindependent manner (24-26). Previous studies have reported that high Cav-1 expression levels are associated with tumor progression and metastasis in prostate and pancreatic cancer, while inhibiting metastasis and tumor progression (27-29). Furthermore, Tu686 and 686LN cell lines, established from pharyngeal squamous cell carcinoma and its metastatic lymph nodes, respectively, were assessed, and it was reported that Cav-1 expression was reduced in 686LN cells compared with Tu686 cells, with greater metastatic and invasive abilities exhibited in 686LN cells (30). However, a comprehensive understanding of the role of caveolin in cancer metastasis is required.

In the present study, the role of Cav-1 in the regulation of HNSCC metastasis was examined, and the mechanism by which Cav-1 regulates TGF- $\beta$ signaling in metastasis and EMT was investigated by silencing Cav-1 using short hairpin (sh)RNA technology.

\section{Materials and methods}

Cell lines. The HNSCC Tu686 cell line, provided by the Winship Cancer Institute of Emory University (Atlanta, GA, USA) and established from a primary base of tongue tumor (31), was used in the present study. The cells were maintained as monolayer cultures in DMEM/F12 (1:1) (Gibco/Brl; Thermo Fisher Scientific, Inc., Waltham, MA, USA) supplemented with $10 \%$ fetal bovine serum (Gibco/Brl; Thermo Fisher Scientific, Inc., Waltham, MA, USA) at $37^{\circ} \mathrm{C}$ with $5 \% \mathrm{CO}_{2}$.

Construction of Cav-1 shRNA and the cDNA plasmid vector. shRNA expressing vector pLKO.1-puro was purchased from Addgene, Inc. (Cambridge, MA). Three putative candidate sequences were designed using the Oligoengine software (version 2; www.oligoengine.com), with their specificities confirmed by nucleotide BLAST searches. The two putative candidate sequences and a scramble sequence were as follows: Sequence-1, sense 5'-CCGGGTACATCCATTATAAGCTGC TCGAGCAGCTTATAATGGATGTACTTTTTG-3' and antisense 5'-AATTCAAAAAGTACATCCATTATAAGC TGCTCGAGCAGCTTATAATGGATGTAC-3'; Sequence-2, sense 5'-CCGGGCCGGCGACGACTTCTCCCCTCG AGGGGAGAAGTCGTCGCCGGCTTTTTG-3' and antisense 5'-AATTCAAAA AGCCGGCGACGACTTCTC CCCTCGAGGGGAGAAGTCGTCGCCGGC-3'; Controlsequence, sense 5'-CCGGAGCGTTCACTCCCAACCTGC TCGAGCAGGTTGGGAGTGAACGCTTTTTTG-3' and antisense 5'-AATTCAAAAAAGCGTTCACTCCCAACC TGCTCGAGCAGGTTGGGAGTGAACGCT-3'.

A total of $4.0 \times 10^{4}$ cells were inoculated per well in a 24-well plate for $24 \mathrm{~h}$, and three uniformly distributed wells were selected at $60 \%$ confluency. First, $500 \mu \mathrm{l}$ cell culture containing polybrene at a final concentration of $5 \mu \mathrm{g} / \mathrm{ml}$ was added to the three wells. Subsequently, the two experimental groups (Cav-1 shRNA lentiviral particle suspension, sequence-1 or sequence-2; $80 \mu \mathrm{l}$ ), the negative control group (negative control lentiviral particle suspension; $80 \mu \mathrm{l})$ and the green fluorescent protein (GFP) group (control group lentiviral particle suspension containing the fluorescent GFP marker to observe the transfection efficiency; $80 \mu \mathrm{l}$ ) were incubated at $37^{\circ} \mathrm{C}$ with $5 \% \mathrm{CO}_{2}$ overnight. The medium (DMEM; Gibco/Brl; Thermo Fisher Scientific, Inc.) containing viral particles was changed with fresh medium every 2 days. The selection medium containing puromycin $(5 \mu \mathrm{g} / \mathrm{ml})$ was added to screen positive clones from the third day. After four weeks, a positive clone cell line (Tu686 ${ }^{\mathrm{Cav}-1 \mathrm{RNAi+}}$ ) was selected, cultured and expanded.

Western blot analysis. Cells were lysed in radioimmunoprecipitation assay buffer (Beijing Solarbio Science and Technology Co., Ltd., Beijing, China), for protein extraction. Equal amounts of total protein $(100 \mu \mathrm{g})$, measured by the bicinchoninic acid method, were separated by $12 \%$ SDS-PAGE electrophoresis and transferred onto polyvinylidene fluoride membranes. The membrane was placed in a blocking buffer (cat. no. P0023B; Beyotime Institute of Biotechnology) for $1 \mathrm{~h}$. The membrane was incubated with primary antibody (rabbit anti-human Cav-1 polyclonal antibody; cat. no. PA1-064; 1:800; Santa Cruz Biotechnology, Inc, Dallas, CA, USA) at room temperature for $2 \mathrm{~h}$ followed by incubation with horseradish peroxidase-conjugated rabbit anti-goat antibody (Beyotime Institute of Biotechnology, Haiman, China; 1:1,000) at room temperature for $2 \mathrm{~h}$. Other primary antibodies included mouse anti-human E-cadherin polyclonal (Cell Signaling Technology, Inc.; cat. no. sc-8426; 1:400), mouse anti-human vimentin polyclonal (Cell Signaling Technology, Inc.; cat. no. sc-32322; 1:200), mouse antihuman Smad 2 monoclonal (Cell Signaling Technology Inc.; cat. no. 3103s; 1:800), rabbit anti-human p-Smad2 polyclonal (Cell Signaling Technology, Inc.; cat. no. ser465/467; 1:800) and mouse anti-human $\beta$-actin monoclonal (Beyotime Institute of Biotechnology; cat. no. AF0003; 1:1,000) antibodies. Horseradish peroxidase-conjugated goat anti-mouse and anti-rabbit secondary antibodies (Beyotime Institute of Biotechnology; cat. nos. A0562 and A0568; 1:1,000) were incubated for $2 \mathrm{~h}$ at $37^{\circ} \mathrm{C}$. The membrane was subsequently washed and treated with Pierce enhanced chemiluminescence (ECL) western blotting substrate (Thermo Fisher Scientific, Inc.). Immunoreactive bands were visualized by ECL on a LAS4000 imager and densitometric analysis was performed using Image Quant LAS 500 (GE Healthcare, Chicago, IL, USA).

CCK- 8 assay. CCK-8 assay was used to evaluate proliferation. Following transduction of control shRNA sequence and the experimental sequence for $24 \mathrm{~h}$, respectively, Tu686 cells were seeded in 96-well plates at 5,000 cells/well. After 1-7 days of culture at $37^{\circ} \mathrm{C}$ with $5 \% \mathrm{CO}_{2}, \mathrm{CCK}-8$ (Beyotime Institute of Biotechnology) was added to the cells (10 $\mu \mathrm{l} /$ well $)$, which were further incubated for $1 \mathrm{~h}$ at $37^{\circ} \mathrm{C}$. Absorbance was measured at a wavelength of $450 \mathrm{~nm}$ on a microplate reader (Bio-Rad Laboratories, Inc., Hercules, CA, USA). The experiments were performed in triplicate. Semi logarithmic curves for cell survival were drawn by Microsoft Excel 2000 software (Microsoft Corporation, Redmond, WA, USA).

Wound healing assay. Tu686 cells $\left(1 \times 10^{6}\right)$ were seeded in $6-\mathrm{cm}$ plates coated with $10 \mathrm{mg} / \mathrm{ml}$ type I collagen (Advanced Biomatrix). Following incubation for $24 \mathrm{~h}$, the monolayer was disrupted with a cell scraper (1.2 $\mathrm{mm}$ width), and micrographs 

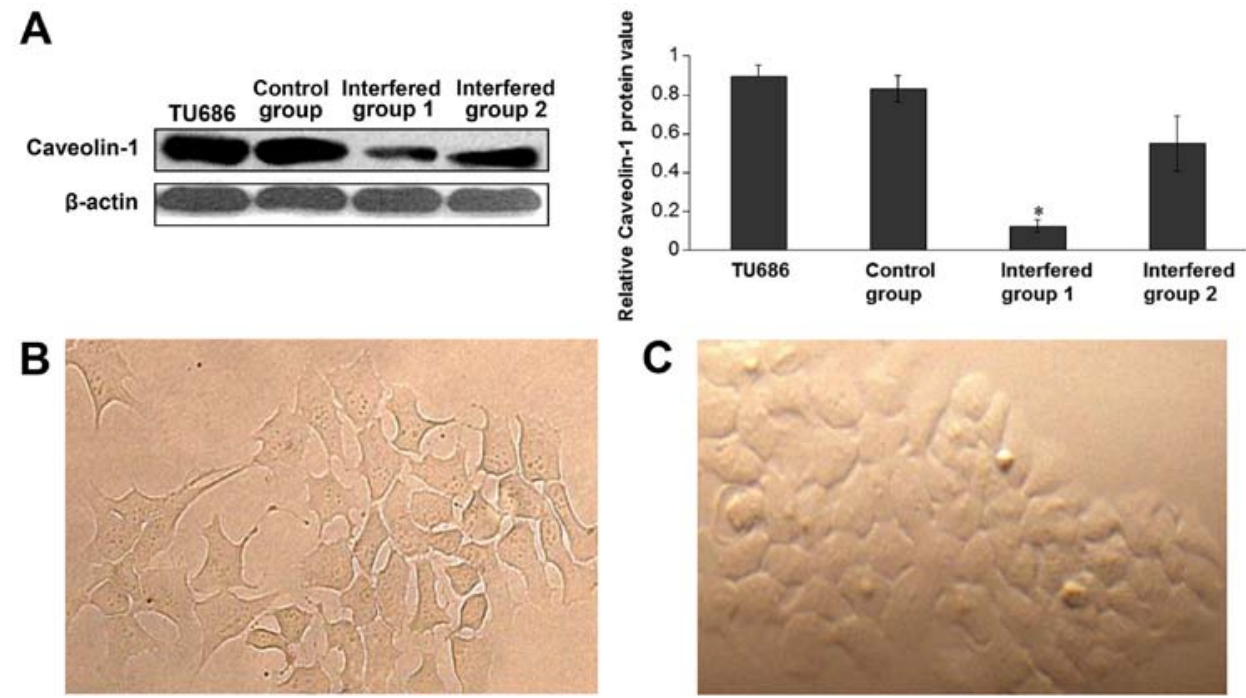

Figure 1. Caveolin-1 knockdown in Tu686 cells by shRNA. (A) Western blot analysis depicting the reduced levels of caveolin-1 following knockdown by shRNA. The levels of caveolin-1 in the interfered group1 were significantly inhibited. Data were analyzed using the Student's t-test. "P<0.05. (B) Cells with silenced caveolin-1 expression exhibited loss of the adherent phenotype with cellular elongation, decreased cell-cell contact, and a fibroblast-like appearance. Magnification, x100. (C) Control cells presenting with pebble-like shape and cell-cell adhesions. Magnification, x100. shRNA, short hairpin RNA.

were acquired at 0 and $24 \mathrm{~h}$ on a phase contrast microscope (magnification, x50; Olympus Corporation, Tokyo, Japan). Experiments were performed in triplicate, and four fields of view in each data point were recorded in a blinded manner.

Transwell assay. For invasion assay, the upper chambers of Matrigel pre-coated Transwell inserts (cat. no. ECM550; Chemicon International, USA.) prior to addition of Tu686 cells $\left(2 \times 10^{4}\right)$. The lower chambers were filled with $0.8 \mathrm{ml}$ conditioned DMEM supplemented with $10 \%$ fetal bovine serum (Gibco/Brl; Thermo Fisher Scientific, Inc., Waltham, MA, USA ) to induce chemotaxis in Tu686 cells. After $24 \mathrm{~h}$ of incubation at $37^{\circ} \mathrm{C}$, the cells were fixed in $4 \%$ methanol at room temperature $\left(25^{\circ} \mathrm{C}\right)$ for $10 \mathrm{~min}$ and stained with hematoxylin and eosin at room temperature $\left(25^{\circ} \mathrm{C}\right)$ for $30 \mathrm{~min}$. Cells that invaded through the pores to the lower side of the filter were counted under an inverted light microscope (magnification, x100; Olympus Corporation, Tokyo, Japan). Three migration chambers were used for each condition and the mean number of cells was calculated.

Activation of the TGF- $\beta 1$ signaling pathway in TU686 cells. Logarithmic growth was observed in Tu686 cells, using serum for $12 \mathrm{~h}$ prior to withdrawal and culture for $24 \mathrm{~h}$ at $37^{\circ} \mathrm{C}$, maintaining parameters, including cell confluence of $80-90 \%$, $0.25 \%$ trypsin $+0.02 \%$ EDTA digestion and density adjustment to $2.5 \times 10^{4}$ cells $/ \mathrm{ml}$. The cells were maintained in $50 \mathrm{ml}$ disposable cell suspension culture bottles at $37^{\circ} \mathrm{C}$ and $5 \% \mathrm{CO}_{2}$ for $24 \mathrm{~h}$ with serum-free DMEM/F12 for $24 \mathrm{~h}$. Subsequently, five groups were set up with TGF- $\beta 1$ (cat. no. 100-21/100-21C; PeproTech US, Rocky Hill, NJ, USA) at the final concentrations of 5, 10, 15, 20 and $25 \mathrm{ng} / \mathrm{ml}$, diluted with serum-free DMEM/F12 to $4 \mathrm{ml}$, and incubated at $37^{\circ} \mathrm{C}$ with $5 \% \mathrm{CO}_{2}$ for $48 \mathrm{~h}$. The cells were subsequently collected for further experiments.

Immunofluorescence. For the immunofluorescence staining, Tu686 cells $\left(4 \times 10^{4}\right)$ grown on coverslips were fixed with warm
PHEMO buffer (68 mM PIPES, 25 mM HEPES, pH 6.9, 15 mM EGTA, $3 \mathrm{mM} \mathrm{MgCl}_{2}$ ), and $10 \%$ (v/v) DMSO containing $3.7 \%$ formaldehyde, $0.05 \%$ glutaraldehyde, and $0.5 \%$ Triton X-100 for $10 \mathrm{~min}$ at room temperature $\left(25^{\circ} \mathrm{C}\right)$. Cells were blocked with 5\% BSA (cat. no. sw3015; Beijing Solarbio Science and Technology Co., Ltd.) for $1 \mathrm{~h}$ at room temperature $\left(25^{\circ} \mathrm{C}\right)$ and incubated with primary at $37^{\circ} \mathrm{C}$ for $1 \mathrm{~h}$ or at $4^{\circ} \mathrm{C}$ overnight and subsequently with fluorophore-conjugated secondary antibodies at $37^{\circ} \mathrm{C}$ for $1 \mathrm{~h}$, including mouse anti-human Cav-1 polyclonal antibody (cat. no. 610493, BD Biosciences, San Jose, CA, USA; 1:800), mouse anti-human transforming growth factor $\beta 1$ (cat. no. sc-130348; 1:1,000; Santa Cruz Biotechnology, Inc.), and fluorescein isothiocyanate- and rhodamine $\mathrm{B}$ isothiocyanate-conjugated $\mathrm{IgG}$ antibodies (cat. no. zf-0311; 1:100; OriGene Technologies, Inc., Beijing, China). Images were acquired on a Zeiss LSM 510 META confocal microscope (magnification, x630).

Statistical analysis. Statistical analysis was performed with the SPSS 17.0 software (SPSS, Inc., Chicago, IL, USA). Quantitative data are expressed as the mean \pm standard deviation. Statistical significance was estimated by two-tailed Student's t-test or one-way analysis of variance followed by the Student-Newman-Keuls post hoc test. $\mathrm{P}<0.05$ was considered to indicate a statistically significant difference.

\section{Results}

Silencing of Cav-1 expression by shRNA in Tu686 cells. In the present study, shRNA was used to inhibit Cav-1 expression. Candidate sequence 1 significantly inhibited the protein expression of Cav-1 by $>60 \%$ and candidate sequence 2 inhibited the expression by 30-40\%. Control sequences caused no detectable changes in Cav-1 expression (Fig. 1A). These results indicated that candidate sequence 1 was more efficient compared with candidate sequence 2 . A change in cell morphology was also detected following 
A oh

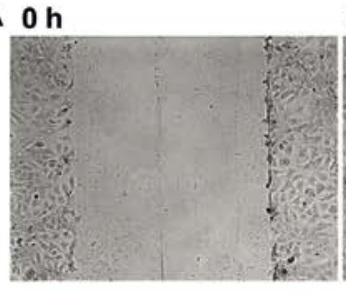

$24 \mathrm{~h}$

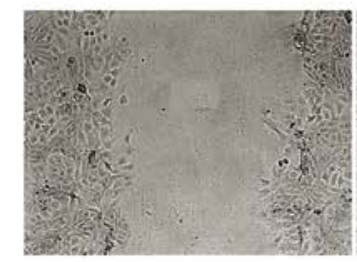

C

Tu686 ${ }^{\text {Cav-1 RNA- }}$

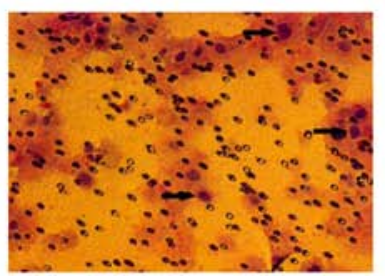

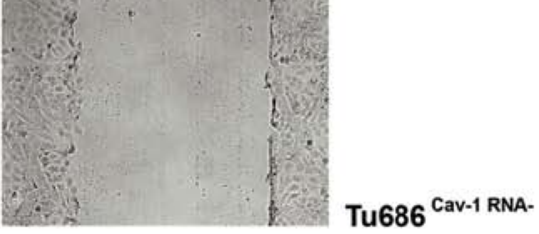

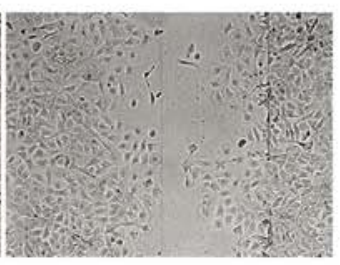

Tu686 ${ }^{\text {Cav-1 RNA+ }}$
B
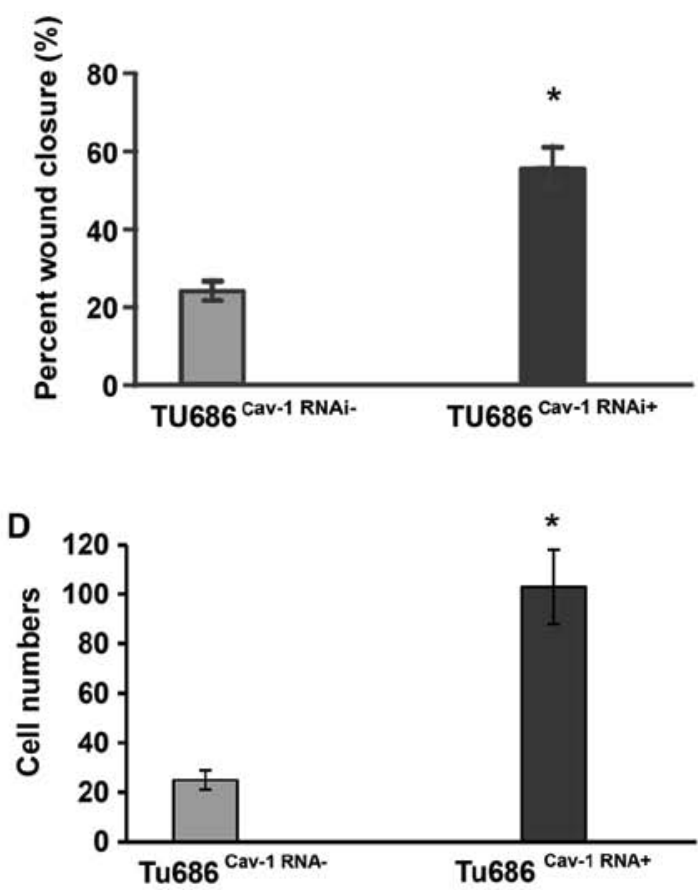

Figure 2. Effects of Cav-1-knockdown by shRNA on cell migration and proliferation in Tu686 cells. (A) Qualitative (magnification, x50) and quantitative (B) wound healing assay results to determine the migration abilities of Tu686 Cav-1RNA- and Tu686 Cav-1RNA+ cells at 0 and 24 h. (C) Qualitative (magnification, $\mathrm{x} 100$ ) and (D) quantitative Transwell assay results to evaluate the invasion abilities of Tu686 $6^{\mathrm{Cav}-1 \mathrm{RNA}-}$ and Tu686 ${ }^{\mathrm{Cav}-1 \mathrm{RNA}+}$ cells. The arrows indicate the stained nuclei of the cells that migrated through the Transwell membrane. Cells were seeded into the upper chamber of the Transwell, and those passing through the pores to the lower side of the filter were counted. Data were analyzed by Student's t-test. "P<0.05 vs. Tu686 ${ }^{\text {Cav-IRNA. }}$ RNAi, RNA interference; shRNA, short hairpin RNA; Cav-1, caveolin-1.

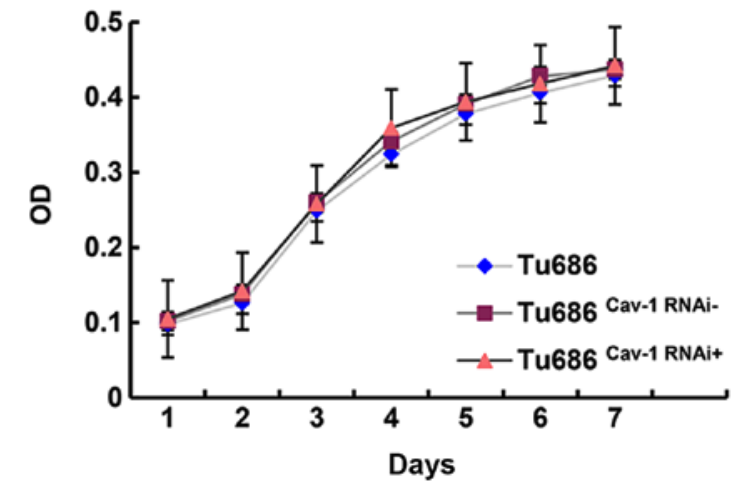

Figure 3. Cell growth and proliferation following Cav-1-knockdown by shRNA. CCK- 8 assay was used to assess the viability and proliferation of Tu686, Tu686 Cav-1RNAi- and Tu686 Cav-1RNAi+ cells. RNAi, RNA interference; shRNA, short hairpin RNA; Cav-1, caveolin-1; OD, optical density.

transfection under an inverted microscope (magnification, x100; Olympus Corporation, Tokyo, Japan), where cells with silenced Cav-1 displayed a spindle shape and pseudopodia, similar to fibroblasts (Fig. 1B). Control cells are presented in Fig. 1C.

Cav-1 promotes migration but not proliferation in Tu686 cells. Taking into consideration that upregulation of Cav-1 expression is associated with HNSCC metastasis (30), we hypothesized that Cav-1 may be involved in the invasive phenotype of HNSCC by promoting cell migration. To test
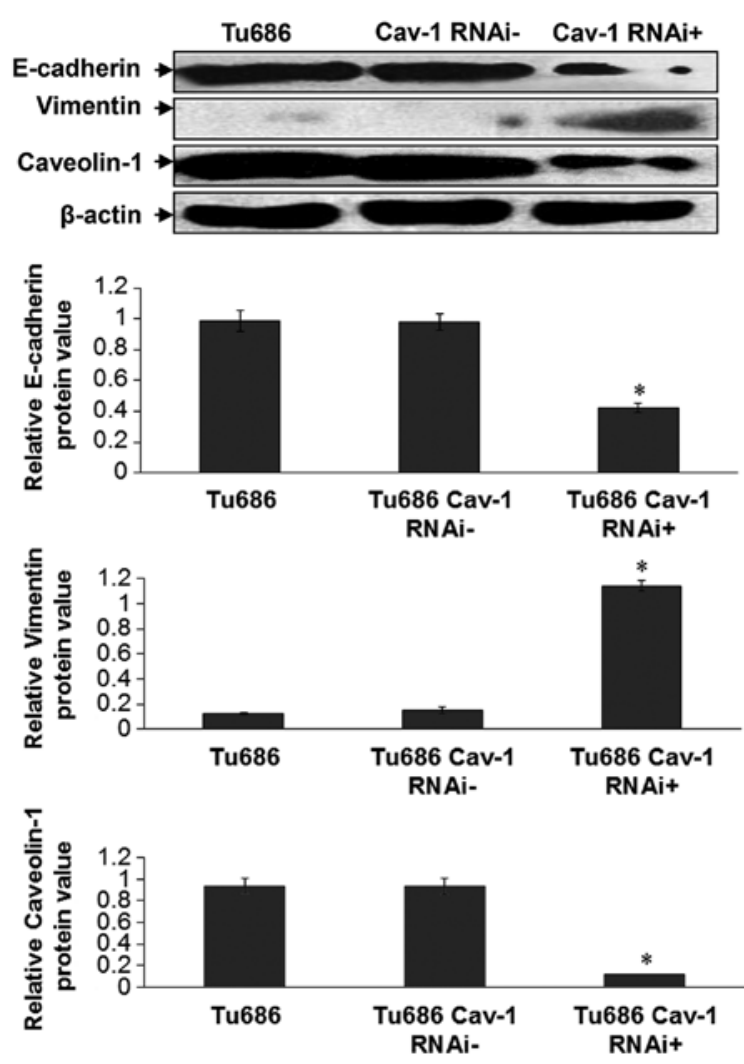

Figure 4. Protein levels of E-cadherin and vimentin following Cav-1-knockdown Knockdown of Cav-1 resulted in vimentin upregulation and E-cadherin downregulation. Tu686 cells were used as the blank control. Tu686 ${ }^{\mathrm{Cav}-1 \mathrm{RNAi}+}$ vs. Tu686 cells and Tu686 ${ }^{\text {Cav-1RNAi- . }} \mathrm{P}<0.05$. RNAi, RNA interference; Cav-1, caveolin-1. 

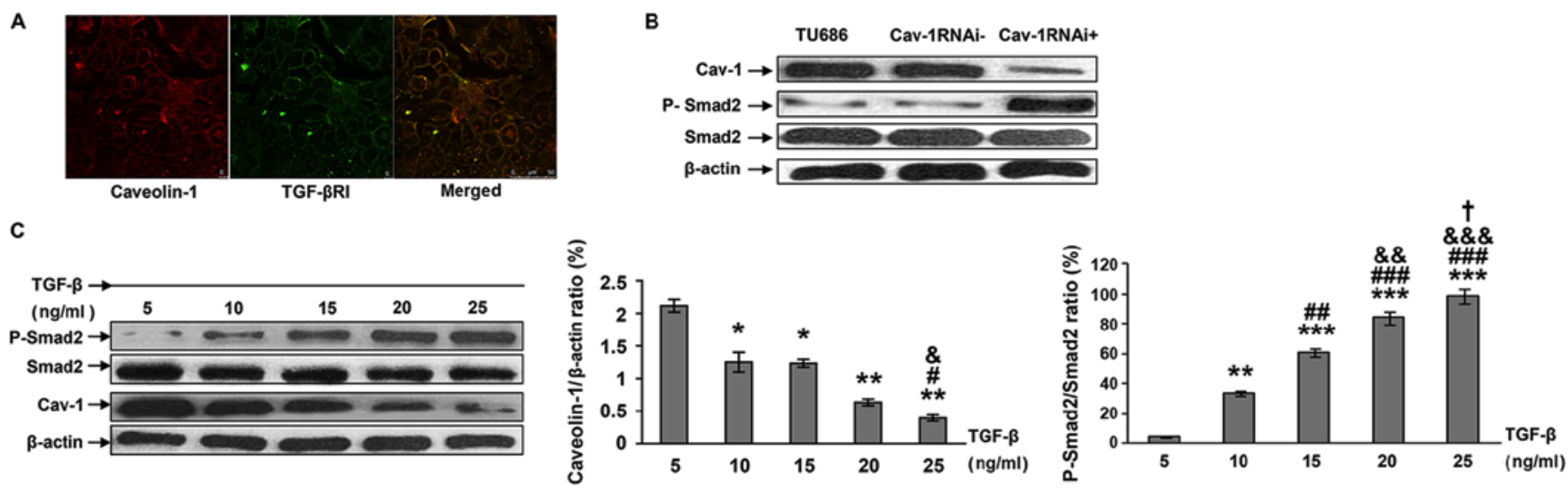

Figure 5. Effects of Cav-1-knockdown on TGF- $\beta 1$ signaling. (A) Double-labeled immunofluorescence was employed to determine the localizations of Cav-1 and TGF- $\beta$ RI in Tu686 cells. Magnification, x630. (B) Knockdown of Cav-1 resulted in increased p-Smad 2 levels. Tu686 cells were used as the blank control. (C) Dose-dependent changes in Smad, p-Smad and Cav-1 protein levels with increasing doses of TGF- $\beta 1$ (5, 10 , 15, 20 and $25 \mathrm{ng} / \mathrm{ml})$ following $48 \mathrm{~h}$ of culture. Quantification of results was performed using one-way analysis of variance and the Student-Newman-Keuls post hoc test. ${ }^{*} \mathrm{P}<0.04,{ }^{* *} \mathrm{P}<0.01$ and ${ }^{* * *} \mathrm{P}<0.001$ vs. $5 \mathrm{ng} / \mathrm{ml}$. ${ }^{\#} \mathrm{P}<0.05,{ }^{\# \#} \mathrm{P}<0.01$ and ${ }^{\# \# \#} \mathrm{P}<0.001$ vs. $10 \mathrm{ng} / \mathrm{ml} .{ }^{\&} \mathrm{P}<0.05$, ${ }^{\&} \mathrm{P}<0.01$ and ${ }^{\& \& \&} \mathrm{P}<0.001$ vs. $15 \mathrm{ng} / \mathrm{ml}$. ${ }^{\dagger} \mathrm{P}<0.05 \mathrm{vs} .20 \mathrm{ng} / \mathrm{ml}$. RNAi, RNA interference; Cav-1, caveolin-1; Smad2, SMAD family member 2 ; TGF- $\beta 1$, transforming growth factor $\beta 1$; $p$, phosphorylated; TGF- $\beta$ RI, transforming growth factor $\beta 1$.

this possibility, the effect of Cav-1 on the metastasis of Tu686 cells was assessed. Wound healing and Transwell assays were employed to determine the migration and invasion abilities of Tu686 cells, respectively. Tu686 ${ }^{\mathrm{Cav}-1 \mathrm{RNAi+}}$ cells exhibited a $15 \%$ increase in wound closure compared with Tu686 ${ }^{\mathrm{Cav}-1 \mathrm{RNAi}}$ cells $(\mathrm{P}<0.05)$ in the wound healing assay. In the Transwell assay, a significantly higher number of Tu686 ${ }^{\mathrm{Cav}-1 \mathrm{RNA}+}$ cells passed through the Matrigel compared with Tu686 ${ }^{\text {Cav-1RNA- }}$ cells, suggesting a role for Cav-1 in the migration of Tu686 cells ( $\mathrm{P}<0.05$; Fig. 2).

A CCK-8 assay was employed to assess the growth and proliferation ability of Tu686, Tu686 ${ }^{\text {Cav-1RNAi- }}$ and Tu686 ${ }^{\text {Cav-1RNAi+ }}$ cells. No statistical differences were identified between the Tu686 and Tu686 ${ }^{\text {Cav-1RNAi- }}$ groups, Tu686 and Tu686 $6^{\text {Cav-1RNAi+ }}$ groups, and Tu686 ${ }^{\text {Cav-1RNAi- }}$ and Tu686 ${ }^{\text {Cav-1RNAi+ }}$ groups ( $\mathrm{P}>0.05$; Fig. 3 ).

Cav-1 silencing upregulates vimentin and reduces $E$-cadherin expression. EMT is marked by two crucial events: Loss of E-cadherin, a transmembrane protein involved in cell-cell adhesion, and an increase in the expression of vimentin, an intermediate filament protein (32). Therefore, the present study assessed the expression levels of these two proteins following Cav-1 silencing. It was indicated that Cav-1 shRNA significantly reduced the expression of E-cadherin and increased that of vimentin in Tu686 cells (Tu686 ${ }^{\text {Cav-1RNAi+ }}$ vs. Tu686 cells and Tu686 ${ }^{\text {Cav-1RNAi-; }}$ P<0.05; Fig. 4).

Cav-1 silencing induces TGF- $\beta 1$ signaling. Confocal microscopy was used to determine the in vivo localizations of Cav-1 and TGF- $\beta 1$ receptors. As indicated in Fig. $5 \mathrm{~A}$, TGF- $\beta 1 \mathrm{R}$ and Cav-1 were co-localized inside the cells.

It was also identified that stable silencing of Cav-1 in Tu686 cells led to an increased expression of phosphorylated Smad2, indicating an increased activation of the TGF- $\beta$ pathway (Fig. 5B). A dose-dependent decrease in Cav-1 expression level was observed with gradually increasing TGF- $\beta 1$ levels. These findings suggest a mutual regulation of TGF- $\beta 1$ signaling and Cav-1 (Fig. 5C).

\section{Discussion}

The aim of the present study was to examine the molecular regulation of HNSCC metastasis. The role of Cav-1 in regulating TGF- $\beta$-induced EMT was assessed. Silencing of Cav-1 expression led to reduced E-cadherin expression, cell migration and increased vimentin expression, all key markers of EMT (33). It was also indicated that Cav-1 downregulation resulted in increased TGF- $\beta$ signaling, reflected by increased phosphorylation of Smad2. Therefore, the present study proposes that Cav-1 expression inhibits EMT by regulation of TGF- $\beta$ signaling.

In order to gain novel insights into the role of Cav-1 in HNSCC, shRNA was employed to knockdown Cav-1 expression in Tu686 cells. Cav-1 depletion resulted in increased cell migration, with no significant effects on proliferation. In addition, changes in cell morphology were observed, as cells were spindle-shaped and a number of them presented with pseudopodia, similar to fibroblasts. These findings of morphological changes are in accordance with previous studies on EMT-induced shape changes (34-36). Therefore, downregulation of Cav-1 expression resulted in phenotypic changes similar to EMT in Tu686 cells.

A number of studies have assessed the role of Cav-1 expression during EMT and cancer metastasis. Lu et al (37) demonstrated that EGF-stimulating factor in tumor cells significantly reduced Cav-1 expression, activated the $\beta$-catenin-T-cell factor/lymphoid enhancer-binding factor transcription factor, decreased the levels of the epithelial cell marker E-cadherin, blunted cell-cell contact, and enhanced the cellular phenotypes of EMT and metastasis. Bailey et al (38) indicated that Cav-1 regulation during EMT is mediated by focal adhesion kinase.

Abnormalities in the TGF- $\beta$ signaling pathway are closely associated with tumor cell invasion and metastasis (39). In breast cancer, activated TGF- $\beta$ signaling pathway can cause hypermethylation and subsequent loss of expression of E-cadherin, cingulin, claudin 4 and kallikrein related peptidase 10, resulting in EMT and breast cancer metastasis (40). 
Araki et al (41) reported that activated TGF- $\beta 1$ signaling in breast cancer cells increases the expression of E3 ubiquitin ligase human murine double minute, leading to P53 gene destabilization and the EMT phenotype in cells.

By using confocal microscopy, the present study observed that Cav-1 and TGF- $\beta 1$ receptors were co-localized on the plasma membrane, indicating that the effects of Cav-1 on EMT may involve TGF- $\beta 1$ signaling. Schwartz et al (42) reported that TGF- $\beta$ receptor (TGF- $\beta$ R) I and II co-localize with Cav-1 and nitric oxide synthase 3 (eNOS) in human umbilical vein epithelial cells. They further indicated that TGF- $\beta 1$ interacts and regulates eNOS activity in the caveolae.

In the present study, Cav- 1 could inhibit TGF- $\beta$ signaling by regulating the phosphorylation levels of its downstream effector SMAD2. In addition, Cav-1 silencing significantly increased the expression of phosphorylated Smad2, indicating an induction of TGF- $\beta 1 \mathrm{R}$ II signaling. The present study also indicated a dose-dependent decrease in Cav-1 levels with increasing levels of TGF- $\beta 1$, which further indicates the mutual inhibitory regulation between the TGF- $\beta 1$ signaling pathway and Cav -1 .

A limitation of the current study should be mentioned. Although EMT is a complex event involving transcription factors, cytoskeletal proteins and extracellular matrix components among others (43), E-cadherin and vimentin were only assessed in this experiment; therefore, further comprehensive studies should examine the effects of Cav-1 on other factors affecting EMT.

In conclusion, the present study indicated that Cav-1 may regulate EMT by influencing cell invasion and migration in HNSCC cells. It was further demonstrated that the aforementioned regulation may involve the TGF- $\beta 1$ signaling pathway. The current study also provided a basis for a mutual association between Cav-1 and TGF- $\beta$ signaling for metastasis regulation in HNSCC.

\section{Acknowledgements}

Not applicable.

\section{Funding}

No funding was received.

\section{Availability of data and materials}

All data generated or analyzed during this study are included in this published article.

\section{Authors' contributions}

JS conceived and coordinated the study, designed and performed the experiments, and wrote the manuscript. YL, CY, TX, GN, BM and XZ performed data collection, data analysis and revised the manuscript. All authors reviewed the results and approved the final version of the manuscript.

\section{Ethics approval and consent to participate}

Not applicable.

\section{Patient consent for publication}

Not applicable.

\section{Competing interests}

The authors declare that they have no competing interests.

\section{References}

1. Sanderson RJ and Ironside JA: Squamous cell carcinomas of the head and neck. BMJ 325: 822-827, 2002.

2. Rezende TM, de Souza Freire M and Franco OL: Head and neck cancer: Proteomic advances and biomarker achievements. Cancer 116: 4914-4925, 2010.

3. Chi AC, Day TA and Neville BW: Oral cavity and oropharyngeal squamous cell carcinoma-an update. CA Cancer J Clin 65: 401-421, 2015.

4. Torre LA, Bray F, Siegel RL, Ferlay J, Lortet-Tieulent J and Jemal A: Global cancer statistics, 2012. CA Cancer J Clin 65 87-108, 2015.

5. Ho AS, Kraus DH, Ganly I, Lee NY, Shah JP and Morris LG: Decision making in the management of recurrent head and neck cancer. Head Neck 36: 144-151, 2014.

6. Garavello W, Ciardo A, Spreafico R and Gaini RM: Risk factors for distant metastases in head and neck squamous cell carcinoma. Arch Otolaryngol Head Neck Surg 132: 762-766, 2006.

7. Walsh JE, Lathers DM, Chi AC, Gillespie MB, Day TA and Young MRl: mechanisms of tumor growth and metastasis in head and neck squamous cell carcinoma. Curr Treat Options Oncol 8: 227-238, 2007.

8. Jung AC, Ray AM, Ramolu L, Macabre C, Simon F, Noulet F, Blandin AF, Renner G, Lehmann M, Choulier L, et al: Caveolin1-negative head and neck squamous cell carcinoma primary tumors display increased epithelial to mesenchymal transition and prometastatic properties. Oncotarget 6: 41884-41901, 2015.

9. Ferlito A, Shaha AR, Silver CE, Rinaldo A and Mondin V: Incidence and sites of distant metastases from head and neck cancer. ORL J Otorhinolaryngol Relat Spec 63: 202-207, 2001.

10. Merlano M, Vitale V, Rosso R, Benasso M, Corvò R, Cavallari M, Sanguineti G, Bacigalupo A, Badellino F, Margarino G, et al: Treatment of advanced squamous-cell carcinoma of the head and neck with alternating chemotherapy and radiotherapy. N Eng J Med 327: 1115-1121, 1992.

11. Molinolo AA, Amornphimoltham P, Squarize CH, Castilho RM, Patel V and Gutkind JS: Dysregulated molecular networks in head and neck carcinogenesis. Oral Oncol 45: 324-334, 2009.

12. Choi $\mathrm{P}$ and Chen $\mathrm{C}$ : Genetic expression profiles and biologic pathway alterations in head and neck squamous cell carcinoma. Cancer 104: 1113-1128, 2005.

13. Koshizuka K, Hanazawa T, Fukumoto I, Kikkawa N, Okamoto Y and Seki N: The microRNA signatures: Aberrantly expressed microRNAs in head and neck squamous cell carcinoma. J Hum Genet 62: 3-13, 2017.

14. Hedberg ML, Goh G, Chiosea SI, Bauman JE, Freilino ML, Zeng Y, Wang L, Diergaarde BB, Gooding WE, Lui VW, et al: Genetic landscape of metastatic and recurrent head and neck squamous cell carcinoma. J Clin Invest 126: 169-180, 2016.

15. Gaykalova DA, Mambo E, Choudhary A, Houghton J, Buddavarapu K, Sanford T, Darden W, Adai A, Hadd A, Latham G, et al: Novel insight into mutational landscape of head and neck squamous cell carcinoma. PLoS One 9: e93102, 2014.

16. Heerboth S, Housman G, Leary M, Longacre M, Byler S, Lapinska K, Willbanks A and Sarkar S: EMT and tumor metastasis. Clin Transl Med 4: 6, 2015.

17. Larue L and Bellacosa A: Epithelial-mesenchymal transition in development and cancer: Role of phosphatidylinositol 3' kinase/AKT pathways. Oncogene 24: 7443-7454, 2005.

18. Diepenbruck M and Christofori G: Epithelial-mesenchymal transition (EMT) and metastasis: Yes, no, maybe? Curr Opin Cell Biol 43: 7-13, 2016.

19. Heldin $\mathrm{CH}$, Vanlandewijck $\mathrm{M}$ and Moustakas A: Regulation of EMT by TGF $\beta$ in cancer. FEBS Lett 586: 1959-1970, 2012.

20. Xu J, Lamouille S and Derynck R: TGF-beta-induced epithelial to mesenchymal transition. Cell Res 19: 156-172, 2009. 
21. Lamouille S, Xu J and Derynck R: Molecular mechanisms of epithelial-mesenchymal transition. Nat Rev Mol Cell Biol 15: 178-196, 2014

22. Zavadil $\mathbf{J}$ and Böttinger EP: TGF-beta and epithelial-to-mesenchymal transitions. Oncogene 24: 5764-5774, 2005.

23. Zavadil J, Cermak L, Soto-Nieves N and Böttinger EP: Integration of TGF-beta/Smad and Jagged1/Notch signalling in epithelialto-mesenchymal transition. EMBO J 23: 1155-1165, 2004.

24. Moreno-Caceres J, Caja L, Mainez J, Mayoral R, Martín-Sanz P, Moreno-Vicente R, Del Pozo MÁ, Dooley S, Egea G and Fabregat I: Caveolin-1 is required for TGF- $\beta$-induced transactivation of the EGF receptor pathway in hepatocytes through the activation of the metalloprotease TACE/ADAM17. Cell Death Dis 5: e1326, 2014.

25. Fridolfsson HN, Roth DM, Insel PA and Patel HH: Regulation of intracellular signaling and function by caveolin. FASEB J 28: 3823-3831, 2014

26. Del Galdo F, Lisanti MP and Jimenez SA: Caveolin-1, transforming growth factor-beta receptor internalization, and the pathogenesis of systemic sclerosis. Curr Opin Rheumatol 20 713-719, 2008

27. Sloan EK, Stanley KL and Anderson RL: Caveolin-1 inhibits breast cancer growth and metastasis. Oncogene 23: 7893-7897, 2004.

28. Chatterjee M, Ben-Josef E, Thomas DG, Morgan MA, Zalupski MM, Khan G, Andrew Robinson C, Griffith KA, Chen CS, Ludwig T, et al: Caveolin-1 is associated with tumor progression and confers a multi-modality resistance phenotype in pancreatic cancer. Sci Rep 5: 10867, 2015.

29. Sugie S, Mukai S, Yamasaki K, Kamibeppu T, Tsukino $H$ and Kamoto T: Significant association of caveolin-1 and caveolin-2 with prostate cancer progression. Cancer Genomics Proteomics 12: 391-396, 2015.

30. Zhang H, Su L, Müller S, Tighiouart M, Xu Z, Zhang X, Shin HJ, Hunt J, Sun SY, Shin DM and Chen ZG: Restoration of caveolin-1 expression suppresses growth and metastasis of head and neck squamous cell carcinoma. Br J Cancer 99: 1684-1694, 2008.

31. Sacks PG: Cell, tissue and organ culture as in vitro models to study the biology of squamous cell carcinomas of the head and neck. Cancer Metastasis Rev 15: 27-51, 1996.

32. Thiery JP, Acloque H, Huang RY and Nieto MA: Epithelialmesenchymal transition in development and disease. Cell 139: 871-890, 2009

33. Kalluri R and Weinberg RA: The basics of epithelial-mesenchymal transition. J Clin Invest 119: 1420-1428, 2009.

34. Moreno-Bueno G, Peinado H, Molina P, Olmeda D, Cubillo E, Santos V, Palacios J, Portillo F and Cano A: The morphological and molecular features of the epithelial-to-mesenchymal transition. Nat Protoc 4: 1591-1613, 2009.
35. Yu C, Liu Y, Huang D, Dai Y, Cai G, Sun J, Xu T, Tian Y and Zhang X: TGF- $\beta 1$ mediates epithelial to mesenchymal transition via the TGF- $\beta /$ Smad pathway in squamous cell carcinoma of the head and neck. Oncol Rep 25: 1581-1587, 2011.

36. Pi LM, Liu Y, Yu CY, Cai GM, Hunag DH, Qiu YZ, Tian YQ and Zhang X: EGCG regulates TGF- $\beta 1$-induced epithelial mesenchymal transition in squamous cell carcinoma of head and neck. Zhonghua Er Bi Yan Hou Tou Jing Wai Ke Za Zhi 47: 749-752, 2012 (In Chinese).

37. Lu Z, Ghosh S, Wang Z and Hunter T: Downregulation of caveolin-1 function by EGF leads to the loss of E-cadherin, increased transcriptional activity of beta-catenin, and enhanced tumor cell invasion. Cancer Cell 4: 499-515, 2003.

38. Bailey KM and Liu J: Caveolin-1 up-regulation during epithelial to mesenchymal transition is mediated by focal adhesion kinase. J Biol Chem 283: 13714-13724, 2008.

39. Miyazono K: Transforming growth factor-beta signaling in epithelial-mesenchymal transition and progression of cancer. Proc Jpn Acad Ser B Phys Biol Sci 85: 314-323, 2009.

40. Papageorgis P, Lambert AW, Ozturk S, Gao F, Pan H, Manne U, Alekseyev YO, Thiagalingam A, Abdolmaleky HM, Lenburg M and Thiagalingam S: Smad signaling is required to maintain epigenetic silencing during breast cancer progression. Cancer Res 70: 968-978, 2010.

41. Araki S, Eitel JA, Batuello CN, Bijangi-Vishehsaraei K, Xie XJ, Danielpour D, Pollok KE, Boothman DA and Mayo LD: TGF-beta1-induced expression of human Mdm2 correlates with late-stage metastatic breast cancer. J Clin Invest 120: 290-302, 2010.

42. Schwartz EA, Reaven E, Topper JN and Tsao PS: Transforming growth factor-beta receptors localize to caveolae and regulate endothelial nitric oxide synthase in normal human endothelial cells. Biochem J 390: 199-206, 2005.

43. De Craene B and Berx G: Regulatory networks defining EMT during cancer initiation and progression. Nat Rev Cancer 13: 97-110, 2013.

This work is licensed under a Creative Commons Attribution-NonCommercial-NoDerivatives 4.0 International (CC BY-NC-ND 4.0) License. 